\title{
Memória social e construção de mitos fundacionais: separatismo na Amazônia Oriental
}

\section{Social memory and construction of foundation miths: separatism in Eastern Amazonia}

Idelma Santiago da Silva - Universidade Federal do Sul e Sudeste do Pará, doutora em História (UFG, 2010), professora do Instituto de Ciências Humanas e do Programa de Pós-Graduação em Dinâmicas Territoriais e Sociedade na Amazônia da Universidade Federal do Sul e Sudeste do Pará. E-mail: idelmasantiago@gmail.com

\section{Resumo}

Este trabalho trata do processo histórico de erguimento de memória social, visando legitimar reivindicações de recortes político-territoriais na Amazônia Oriental brasileira. Nestas reivindicações estão imbricados interesses de ordenamento social e de domínio de território pelas denominadas redes do agronegócio (monoculturas e mineração). Neste artigo, abordarei brevemente os casos do Maranhão do Sul (MA) e Carajás (PA). Estão em jogo, como interesse articulador, pretensões de estruturação de arranjos regionais de poder sobre o território e as relações sociais para viabilizar um determinado modelo de desenvolvimento.

\begin{abstract}
This work deals with the historical process of erection of social memory in order to legitimize claims of politicalterritorial clippings in Eastern Amazonia. These claims are overlapping interests of social order and domination of territory by so-called networks of agribusiness (monoculture and mining). In this article I will discuss briefly the cases of South Maranhão (MA) and Carajás (PA). Are at stake, such as interest articulation, claims of regional arrangements structuring of power over the territory and social relations to permit a particular development model.
\end{abstract}

\section{Palavras-chave}

Memória Social. Identidade Regional. Separatismo.

\section{Keywords}

Social Memory. Identity Regional. Separatism. 


\section{INTRODUÇÃO}

Este trabalho trata do processo histórico de erguimento de memória social, visando legitimar reivindicações de recortes político-territoriais na Amazônia Oriental brasileira, desde o último quartel do século XX. No contexto dessas reivindicações estão imbricados interesses de ordenamento social e de domínio territorial pelas redes do agronegócio (monoculturas e mineração). Assim, esta breve abordagem da questão irá enfocar certos discursos de identidade e memória que são produções socialmente motivadas.

A história recente da Amazônia Oriental brasileira é marcada pelas contradições inerentes às políticas oficiais de ocupação da região, na segunda metade do século XX. Elas visaram o controle geopolítico e a exploração econômica do território, possibilitando, por um lado, a apropriação e concentração da terra; por outro, a estruturação de mercado de trabalho (BECKER; MACHADO, 1982). A representação da região como espaço vaz̧io combinava com a sua descrição como espaço da esperança e da possibilidade, o que permitiu, de um lado, condições ideológicas para a ocupação da região; de outro, garantiu o deslocamento de contingentes populacionais para áreas estratégicas ao capital, especialmente reservas de recursos minerais (MORBACH, 1997).

Neste processo de ocupação, o sul do Maranhão e o sudeste do Pará foram interligados por contiguidades. Por isso, desde o último quartel do século XX, os discursos e práticas que visam legitimar e objetivar recortes espaciais regionais têm se atualizado com a implantação de grandes empreendimentos capitalistas que disputam a estruturação de novos arranjos de poder sobre a região. No entanto, os discursos que visam consenso público pela criação dos estados de Carajás (PA) e Maranhão do Sul (MA) são centralizados numa política de identidade, na discriminação político-administrativa, nas distâncias geográficas e dimensões territoriais.

Como as políticas de identidade regional e de invenção de mitos fundacionais são inscritas no campo da memória social, aí travam-se lutas e intervenções sociais. Conforme Certeau (1994, p. 162), a "memória se produz num lugar que não lhe é próprio" porque sob a "forma prática, a memória não possui uma organização já pronta de antemão", mas ela se mobiliza relativamente ao que acontece, e nisso está "sua capacidade de ser alterada" e servir como dispositivo de intervenção social.

O espaço não preexiste a uma sociedade que o encarna. É através das práticas que estes recortes permanecem ou mudam de identidade, que dão lugar à diferença; é nelas que as totalidades se fracionam, que as partes

Novos Cadernos NAEA • v. 17 n. 1 • p. 203-223• jun. 2014 
não se mostram desde sempre comprometidas com o todo, sendo este todo uma invenção a partir destes fragmentos, no qual o heterogêneo e o descontínuo aparecem como homogêneo e contínuo, em que o espaço é um quadro definido por algumas pinceladas (ALBUQUERQUE JR., 2001, p. 25).

A região é “um encontro entre programas de ação. A ‘região’ vem a ser, portanto, o espaço criado por uma interação” (CERTEAU, 1994, p. 212). Por isso, o discurso de elites envolvidas nestes empreendimentos de regionalização, deve ser compreendido pela sua característica dialógica, socialmente localizada (BAKHTIN, 1993) e visando objetivar posicionamentos sociais.

Desta forma, os discursos utilizados neste trabalho podem ser caracterizados como estratificações não apenas de gênero ou profissionais, mas principalmente político-sociais. Para tanto, utilizei-me de fontes variadas que incluem narrativas memorialistas, jornalísticas, acadêmicas e literárias para o desenvolvimento desse tema, ainda que nos limites deste artigo não caiba abordagem mais estendida, acompanhada de todas as citações necessárias.

\section{MARANHÃO DO SUL E AS FRONTEIRAS DO SERTÃO}

No sul do Maranhão, a política de identidade e regionalização tem procurado recriar o sertão - moderno, civilizado e desenvolvido - pelo apossamento de outras identidades a serem destituídas, cultural e materialmente, dos meios de reprodução, de sua existência e como forças concorrentes. A remissão ao passado (sujeito colonizador $=$ sertanejo) serve para reforçar a autoridade desse discurso e instituir seus monumentos como dispositivo de socialização de sentido histórico.

A fronteira se constitui como lugar intersticial, onde cada "objetivo é constituído sobre o traço daquela perspectiva que ele rasura; cada objeto político é determinado em relação ao outro e deslocado no mesmo ato crítico" (BHABHA, 1994, p. 53). Neste sentido, o objetivo de instituição cultural e social do sul do Maranhão relaciona-se com certa dizibilidade de sertão, que desloca e simultaneamente cria novos sentidos. O sertão é como uma zona de solidariedade que possibilita operações de homogeneização, mas que, ao mesmo tempo, precisa construir suas fronteiras internas e passar a limpo o passado (suas contradições e diferenças) para se instituir como espaço estável e natural.

A distância entre o sul e o norte do Maranhão torna-se maior quanto se faz uma análise a respeito dos sertões deste Estado, por serem estes dotados de características próprias quanto à sua forma de colonização -

Novos Cadernos NAEA • v. 17 n. 1 • p. 203-223 • jun. 2014 
vinculados à frente de colonização interiorana ou pastoril nordestina -, às peculiaridades do povo sertanejo, à economia baseada na pecuária e até mesmo à sua paisagem, dotada em sua maior parte de cerrados (REIS; PEREIRA, 2007, p. 11).

O Maranhão do sul continua a mesma saga dos Pastos Bons de outrora. Agora, além dos bandeirantes baianos e pernambucanos, gente de todo o Brasil, como gaúchos, paulistas, mineiros, goianos, nordestinos constituem a identidade deste rincão do Brasil. Uma nação unificada, mas temos um território desconhecido pelos brasileiros do 'sul maravilha' (NOLETO Apud FERREIRA, 2007, p. 28).

Nesses textos, encontram-se marcos do empreendimento envolvendo múltiplas dimensões da realidade da construção de fronteiras internas no Maranhão. Neles estão presentes alguns elementos antigos de interpretação do Brasil, como a dualidade litoral versus sertão. Mas não se trata mais precisamente de uma empreitada para a exposição de uma estigmatização espacial impingida pelo Outro (o litoral), ainda que o argumento da discriminação políticoadministrativa (do governo central) seja recorrentemente empregado. Contudo, elementos tradicionais de representação e categorização do sertão e dos sertanejos são erguidos como um dos lugares de certa objetividade da região. Desse lugar, associado às circunstâncias da reivindicação separatista, uma memória se levanta para inscrever um sul do Maranhão na história. Como nos lembrou Certeau (1994, p. 162), a "sua força de intervenção, a memória a obtém de sua própria capacidade de ser alterada - deslocável, móvel, sem lugar fixo”.

O sertão é reinventado tomando as representações consideradas positivas do passado, como a saga colonizadora dos sertanejos (fazendeiros) criadores de gado, acrescentando, no presente, os novos bandeirantes - os modernos sertanejos do agronegócio. São os marcos de uma nova conquista que se deseja dar ao (re)conhecimento do "sul maravilha". Não é de forma despretensiosa que em determinados discursos de identidade sul-maranhense haja o emprego do termo sulista. É a expressão não apenas de uma alteridade com o norte do estado (o litoral), mas também a idealização de um "regionalismo de superioridade", representado pelo Centro-Sul do país. O ideal de fazer o encontro do paulista com o sertanejo na recriação do novo sertão, moderno, civilizado e desenvolvido.

Pesquisa nas publicações realizadas na região dá conta desse duplo empreendimento, que converge para lutas simultâneas de identidade regional e separatismo político-territorial. Como base legitimadora destas pretensões, salienta-se a construção de uma narrativa de "origem" e permanência de

\footnotetext{
Segundo Albuquerque Júnior (1999, p. 45), o regionalismo paulista é um "regionalismo de superioridade [...] que se sustenta no desprezo pelos outros nacionais e no orgulho de sua ascendência europeia e branca".
} 
especificidades colonizadoras dos sertões maranhenses, tendo como matrizes socioculturais ("civilizadoras") o pioneirismo sertanejo (liberais republicanos/ criadores de gado) e o empreendedorismo dos investidores capitalistas do centrosul do país (modernos/monocultores). No sul/sudoeste do Maranhão está em curso um processo de construção dessa memória histórica e projeto de futuro. E, como toda verdade precisa se instituir publicamente, pode-se compreender que essas publicações têm contribuído para esse "processo de institucionalização" (ALBUQUERQUE JR., s.d., p. 15).

Esse empreendimento não lograria sucesso se não recorresse, seletivamente, a referente de identidade e representações sociais historicamente objetivadas.

[...] é fruto dessa frente interiorana de colonização, responsável por dividir socialmente o estado. Isso significa que o contraste entre o Sul e o Norte do Maranhão vai além da paisagem e dos aspectos econômicos. A identidade do povo sertanejo marca profundamente o fator cultural. Sua simplicidade, seu espírito corajoso e sua composição étnica refletiram na formação da personalidade, no sotaque, na aparência física, no comportamento e nos costumes e tradições mantidas pelo sul-maranhense (REIS; PEREIRA, 2007, p. 20).

Este é um discurso comprometido com a pretensão emancipacionista e assume a narrativa do colonizador, tal qual "o que parece representar a Identidade do Sul do Maranhão [...] mantém o espírito guerreiro e altivo dos sertanejos do século XIX” (SANTOS et al., 2009, p. 20). Uma identidade que teria sido forjada não apenas pelo isolamento e independência econômica, mas também ideológica. Destaca o espírito nativista e libertário dos sertanistas e as revoltas como tentativas de "afirmação e elaboração de uma Identidade Sul-maranhense por parte de muitos fazendeiros" (p. 25). Neste caso, uma identidade que se assenta na defesa das tradições, numa "história pronta, já feita pelos outros, pelos antigos” (ALBUQUERQUE JR., 1999, p. 85), cujo legado permanece, por exemplo, na luta pela emancipação político-territorial.

[...] um dedicado amor à terra, à propriedade, à família e sobretudo à herança no sentido mais amplo e profundo, a tudo dos mais antigos, dos pais aos ascendentes mais distantes. [...]

A formação da Identidade Sul-maranhense foi, dessa forma, delineandose, agregando ao seu núcleo social hábitos e costumes provenientes de diversas regiões do país, ou seja, constituindo-se também de mineiros, paulistas, gaúchos, paraenses [sic], goianos etc. O grupo social que tinha na fazenda o eixo sobre o qual giravam os hábitos e a economia passa a demonstrar suas potencialidades na exploração, além do gado, de novos ramos de atividade econômica, destacando-se investimentos no comércio de bens e serviços, na soja e no ecoturismo, dentre outros, o que vai 
modelando cada vez mais nitidamente a independência da capital em termos econômicos (SANTOS et al., 2009, p. 27-28).

A referência à agregação de novos sujeitos e costumes serve para ressaltar um ideal de heterogeneidade e intercâmbio cultural que as migrações teriam proporcionado ao sul do Maranhão, e que o distinguiria do norte do estado, considerado portador de uma identidade "aparentemente homogênea" (SANTOS et al., 2009, p. 34). Contudo, devido à característica quase panfletária do discurso, as inconsistências são recorrentes. Nesta situação em análise, por exemplo, há uma naturalização dos processos de distinção, quando afirma que o povo desta região "já possuía uma predisposição para ser distinto" se refere a uma "aparentemente Identidade homogênea" do norte, destacam-se, no entanto, as manifestações culturais de matrizes africanas ou afro-indígenas, e ressalta que

Além da influência europeia, a identidade do Norte do Maranhão recebeu contribuições de africanos e nativos, miscelânea essa que fez a diferença na vida da população, que foi se adaptando ao novo estilo de vida, em meio a visíveis diferenças sociais. $\mathrm{O}$ escravo africano foi a mão-de-obra utilizada na lavoura e, como constituía a maior parte da população, predominaram sua cultura e estilo de vida (SANTOS et al., 2009, p. 33).

Temos, então, a idealização do sul maravilha e certa estigmatização do norte, para estabelecer uma diferenciação sociocultural, além de uma denominada fronteira econômica, como veremos adiante. O norte é o exemplo do que o sul não quer ser, o modelo contra o qual se elabora "a imagem civilizada do Sul" (ALBUQUERQUER JR., 1999, p. 61). Essa dualidade norte-sul, reativada nestes discursos, parece dialogar com narrativas passadas sobre o território brasileiro e suas gentes, e que impingiram imagens pejorativas sobre as populações do norte, baseadas em visões deterministas geográficas e critérios biológico-raciais.

A propósito do trabalho de Santos et al. (2009), pode-se compreender que, embora os indígenas e negros integrem uma política de identidade, da qual não participam como agentes da história e sujeitos de memória, essa identidade parece representar o indício de uma permanência sobre as populações do interior do Maranhão: o estigma do caboclo maranhense.

Nesses relatos estão os indícios de que nem todos os sertanejos estão incluídos nessas narrativas de passado e futuro que atualmente se constroem sobre o sul do Maranhão. Em obras descritivas ou memorialistas que participam

2 "A região é inscrita no passado como uma promessa não realizada, ou não percebida; como um conjunto de indícios que já denunciavam sua existência ou a prenunciavam" (ALBUQUERQUE JR., 1999, p. 75).

Novos Cadernos NAEA • v. 17 n. 1 • p. 203-223 • jun. 2014 
desse empreendimento de constituição da "memória regional", são proeminentes determinados recortes como classe social e categorização étnica. A memória que serve às atuais pretensões são aquelas que dão visibilidade à atuação daqueles personagens que ocuparam, simultaneamente, as posições sociais de fazendeiro, comerciante e político (COELHO, 2005; AMORIM, 2008).

Por este viés, percebe-se a permanência de um contraste, que nos remete às obras de Orlando Valverde [1957] e Manuel de Andrade [1968]. Numa vertente, os caboclos maranhenses, no sul do Maranhão, são constituídos de migrantes do litoral que adentraram os sertões pelos rios Itapecuru, Mearim, Pindaré e Grajaú. Seriam esses os representados pejorativamente como indolentes, desambiciosos, negros remanescentes da escravidão, derrotados - a "civilização do babaçu" (ANDRADE, 1977). Certas publicações sobre a história do sul do Maranhão afirmam que, devido à predominância da atividade de criação extensiva de gado, a presença de população escrava teria sido reduzida (CABRAL, 2002 apud REIS; PEREIRA, 2007). Noutra, as características do caboclo nordestino ligadas ao sertão, à migração, sem o estigma da escravidão e lutador constitui o desbravador dos sertões (ANDRADE, 1977). Segundo Guillen (2002), a representação do sertanejo como um forte é um dos estereótipos do nordestino.

Nestes processos de invisibilidade de indígenas e negros, os discursos de identidade em prol da criação do estado do Maranhão do Sul procuram minimizar ou invisibilizar também os personagens da frente de migração nordestina do século XX. Foram camponeses, no geral, populações afro-indígenas que realizaram processos de migração forçada devido à concentração fundiária e às secas no Nordeste. Além disso, no próprio sul do Maranhão, ainda no século XIX, as relações de solidariedade e intercâmbios entre indígenas e negros formaram uma parcela da população do interior do Estado e que sofrem o mesmo estigma e os processos de expropriação dos seus territórios. Na Amazônia Oriental brasileira, a existência de mocambos que reuniram negros e índios foram comuns tanto no Pará como no Maranhão. Nos sertões de Pastos Bons, por exemplo, as descrições de Paula Ribeiro (1819) dão notícias de que os índios abrigavam negros fugidos da escravidão.

O discurso de identidade, que invisibiliza ou nega, como sujeitos de memória, determinados grupos socioculturais no sul do Maranhão, articula preconceitos étnicos, interesse de classe social e de poder sobre o território, e as relações sociais. É, decerto, uma tentativa de ocultar a existência e o direito desses sujeitos em permanecer e dar continuidade às suas vidas nos seus territórios, que tem sido alvo, nas últimas décadas, do interesse de expansão da monocultura praticada pela agricultura capitalista. Ou, também, a tentativa de manter a 
visibilidade pelo estereótipo discricionário que ajuda a legitimar pretensões de expropriação, com base em argumentos modernizadores.

Os trabalhos analisados participam desse processo de realização e seleção das memórias e práticas, que serão erguidas na constituição do sul do Maranhão. A evidência de que não se trata de um processo natural e, sim, de ato social de criação, é, por exemplo, o modo como as diferentes áreas de cerrado e floresta da pré-Amazônia são incorporadas numa contiguidade de identidade homogênea. Nisso está a exposição de que o recorte do sertão é aquele território pretendido num projeto moderno de colonização sertaneja, isto é, o espaço onde visam fazer reconhecer uma identidade social (CHARTIER, 1991) sobre o apossamento de outras identidades a serem destituídas, cultural e materialmente, dos meios de sua reprodução e instituição como forças concorrentes.

Por isso, uma narrativa de "origem" tenta se estabelecer erguendo seus monumentos, que dão testemunho dos atos originários e legitimam determinados sujeitos da história, enquanto apagam não somente as memórias polêmicas, mas outras possibilidades de projetos de futuros. A categoria de sertanejo serve como noção na qual se imprimem os significados e valores que interessam identificar esses grupos no presente, portadores de um projeto de dominação das relações sociais e de exploração exaustiva dos recursos do território, porque, na verdade, ela não representa um ideal estável no tempo e no espaço, e nem para os diferentes sujeitos. A remissão ao passado serve para reforçar a autoridade desse discurso, e instituir seus monumentos como dispositivos de socialização de sentido histórico que, apesar de pertencer a um grupo específico, passa a ser adotado por outras coletividades, podendo conquistar níveis de consenso público.

\section{CARAJÁS: PRÁTICAS E REPRESENTAÇÕES DE REGIONALIZAÇÃO}

$\mathrm{O}$ que se discute neste trabalho serve para refletir como os mitos podem ser colocados a serviço da história e, principalmente, como eles se situam "em momentos de transformações ou rupturas, crise de ordem política, econômica ou social" (TEAO, 2008, p. 6). Os mitos fundadores das "regiões" nas pretensões de separatismo são evidências da reinvenção, que caracteriza a produção dos mitos, porque coloca em relevo a dinâmica reconstrutiva (dialética presente-passadofuturo) da memória e sua atuação na configuração de narrativas fundacionais.

Os sujeitos sociais migrantes envolvidos nas diferentes frentes de ocupação do atual sudeste do Pará (reivindicado para a criação do estado de Carajás), ao longo século XX, adotaram estratégias concorrentes de (re)fundação

Novos Cadernos NAEA • v. 17 n. 1 • p. 203-223 • jun. 2014 
do território. Um primeiro momento foi quando os denominados "pioneiros" construíram os indígenas como o Outro, objetivando a sua eliminação e a apropriação de suas terras. Esse era o contexto da economia da castanha-dopará, e que institucionalizou uma estrutura de poder e prestígio, tendo como figuras centrais o fazendeiro e o comerciante da castanha.

É na ocorrência da disputa com os indígenas pela terra e recursos naturais que se assenta a narrativa dos "pioneiros", como migrantes fundadores do território. Uma refundação que se fez pela tentativa de "eliminação" dos indígenas das terras e da história do médio Tocantins. O "bago" fundou um novo território numa "desconhecida terra de ninguém".

Mas, para enfocá-la desde os tempos pioneiros da conquista da desconhecida terra de ninguém - a zona fisiográfica do Itacaiúnas preferimos chamá-la simplesmente castanha, ou, mais simplesmente ainda 'o bago' [...]

- Vou pro bago! Grito de guerra solto no agreste goiano e nos tabuleiros do Maranhão e, também, pelos beiradões do Tocantins e do Araguaia acima, nos confins onde cochilava a velha cidade de Frei Gil Vila Nova, a dominicana Conceição do Araguaia. [...]

- Olha o bago, moçada!

E, a este grito, os patrões sertanejos deixavam as fazendolas, os 'comércios', os engenhos e as lavouras, e, de mistura com os castanheiros, desciam o rio na cabeça das enxurradas. As primeiras levas, mais numerosas, desciam o Tocantins, vindas de Boa Vista, agora Tocantinópolis, de Santo Antonio, que é agora Itaguatins, e engrossavam no porto de Imperatriz. Eram as cabroeiras de Simplício Moreira, dos Maranhão, dos Lopes e dos Milhomem, dos Chamon e de Isaac Araújo, famoso por causa do 'Ciriqueira Campos', ou Cerqueira Campos, desconforme batelão capaz de engolir 300 barricas! E vinha também a cabroeira dos Mórba, de seu Guimarães.

Vinham em esteiras largas sobre o dorso do rio, marcando os mesmos pousos, de sorte que a 'miunçaia' não chegasse à frente dos patrões acomodados nas capitâneas, comandando a marcha. Eram batelões de dez vogas, 'reboque' de quatro remos, montariões com jacumanzeiro e dois no banco do meio, e ainda os solitários, aqueles que viajavam sozinhos, na cadência dos rojões de viagem longa. Eram espécimes que se destacavam pelo comportamento e pela produção nos castanhais. Mereciam consideração (MORBACH, 1984, p. 118-119).

Nessa narrativa, pioneiros não são todos os migrantes. Há gradações: os "patrões sertanejos", de um lado, e a "cabroeira", a "miunçaia", de outro. Fora "aqueles que viajavam sozinhos". Mas, ela reconhece como tais aqueles oriundos do antigo norte de Goiás e do Maranhão. Essa frente de migração tem suas histórias dignificadas na memória social local, mesmo após as "refundações" posteriores. 
A categoria "pioneiro", empregada em diferentes "acontecimentos discursivos" - memorialísticos e político-panfletários -, refere-se aos (auto) denominados "desbravadores", da primeira metade do século XX. Faz parte de uma memória que tem reificado a história vivida, especialmente na reiteração dos personagens-heróis da conquista, sublinhando o papel dos "coronéis" - os "patrões sertanejos” do Maranhão e antigo norte de Goiás.

Uma segunda in(ter)venção de território aconteceu a partir da década de 1970. Neste contexto, os usos e as interpretações da migração pelos sujeitos migrantes e pelos "regionais" que já se encontravam na área, constituem parte importante das lutas de representação. Parcela desses últimos é "confundida" com os caboclos e a "civilização" será obra dos migrantes do Centro-Sul do país.

Há poucos anos atrás, era justo que se encontrasse, nas margens do Tocantins, o homem denominado 'CARAJÁ'. Bastava ser analfabeto e não saber se vestir bem, para ser um 'CARAJÁ'. UM BAIANO SEM SER DA BAHIA ou o caboclo na expressão mais vulgar. Agora o homem está voltando ao HUMANO (SÁ, 1971. p. 2).

Por outro lado, é exatamente a partir desse momento, especialmente na década de 1980, que a atualização da memória do "pioneiro" é demandada. Neste contexto, de qualquer modo, os antigos estereótipos ou a categorização dos indígenas como caboclos permanece, até porque nessa atualização da memória do pioneiro, o indígena mantém-se como o elemento de alteridade simultaneamente ameaça e possibilidade da identidade do pioneiro. Isso também porque na materialização do novo modelo de ocupação, desde a década de 1970, essas narrativas "renovam-se" no diálogo com as visões estereotipadas e discriminatórias que os "novos" atores políticos e econômicos reproduziram sobre as populações locais subalternizadas: "Índios, negros (quilombolas) e caboclos têm sido considerados nos planos e nos projetos econômicos para a região como sendo portadores de uma cultura pobre, primitiva, tribal e, portanto, inferior" (LOUREIRO, 2002, p. 114). Para os indígenas, as duas frentes de ocupação do médio Tocantins foram igualmente trágicas.

A questão da alteridade sempre foi muito problemática nesses deslocamentos territoriais de populações étnicas e culturalmente diferentes. O momento mais dramático, e até trágico, foi sem dúvida o dos anos setenta e oitenta. As revoltas indígenas atenuaram a tragédia e de algum modo ajudaram muito na criação de uma cultura do reconhecimento dos méritos, virtudes e direitos das populações indígenas. O mesmo não aconteceu com os posseiros da frente de expansão, basicamente porque duplamente estigmatizados: de um lado, como inimigos reais das populações indígenas; de outro lado, porque definidos como inimigos reais do progresso econômico (MARTINS, 2004, p. 7).

Novos Cadernos NAEA • v. 17 n. 1 • p. 203-223 • jun. 2014 
Em 2004, o jornal Correio do Tocantins publicou, no espaço de seu Editorial, por ocasião da data comemorativa da emancipação político-administrativa do município de Marabá, um texto com o título "A luta dos desbravadores contra os índios, as feras e os insetos". Ele evidencia a posição conservadora que tem se mantido nas narrativas sobre os índios, especialmente nomeados "traiçoeiros" e "selvagens" em guerra contra os "brancos". Além disso, deslegitima-se a ação dos indígenas na defesa de seus territórios: "O índio defendendo terras que consideravam suas e o civilizado, por sua vez, tinha a meritória incumbência de desbravá-las e integrá-las à civilização para aproveitamento de suas riquezas e cultivo do solo" (CORREIO DO TOCANTINS, 2004, p. 2).

A narrativa do pioneiro se constrói exatamente quando a contraposição "real" era com o avanço da frente capitalista do centro-sul do país sobre a região. Apesar de os indígenas predominantemente constituírem os Outros dessa narrativa, ela é elaborada por uma elite regional que pretende marcar sua posição num contexto de relações de forças, que podia tornar-se desfavorável à permanência de sua hegemonia socioeconômica. Essa elite rivaliza e/ou solidariza-se com os novos personagens, nomeados ou autoidentificados como "bandeirantes" ou simplesmente "paulistas". Desde então, tiveram que enfrentar a concorrência do discurso do "bandeirante" como aquele que funda ou deve fundar o "novo" território.

A narrativa da colonização da região Norte do Brasil neste período, guarda os mesmos sentidos. Segundo Guimarães Neto (2005, p. 520), a palavra colonização deseja uma positividade, que "traduz políticas de dominação, nas quais a principal questão é a disputa pela terra, e nas quais se estabelece o direito de quem nela pode fixar-se, trabalhar e projetar o seu futuro". Segundo Martins (O SÃO PAULO, 12/04/1980, p. 6-7), este é o momento de realização de "outro modelo de ocupação, que pretende anular e revogar os modelos anteriores. [...] É bem clara a origem regional e social desses invasores. Eles vêm do sul e do sudeste e estão procedendo a uma verdadeira sulização do norte. São de preferência paulistas". Ainda segundo Martins (1980), os dados revelavam que naqueles últimos anos os paulistas já eram proprietários de $15,3 \%$ da área cadastrada pelo Incra no estado do Pará. Todavia, a afirmação de Martins sobre uma "verdadeira sulização do norte" soa exagerada, principalmente porque as antigas elites (oligarquias) regionais tiveram seus interesses favorecidos nas ações do governo federal na região (PETIT, 2003).

Esses "novos" e antigos personagens implantaram empreendimentos econômicos que demandavam trabalhadores e também a "eliminação" daqueles, real ou potencialmente, concorrentes pelo território e seus recursos. O que se viu construir desde então, especialmente a partir da década de 1980, foi o 
rebaixamento moral e sociocultural de determinados grupos de migrantes. O Outro é agora também migrante dessa nova frente de ocupação, mas não é o "bandeirante". O discurso da migração começa a operar para produzir os sentidos das relações para "fora" e para "dentro" da região.

A maioria dos migrantes das últimas três décadas do século XX, para o sudeste do Pará, é constituída de grupos subalternizados. Os sentidos dos deslocamentos foram diversos. Na década de 1970, predomina a migração de camponeses em busca de terras livres para "ocupar" e se reproduzir; na década seguinte, simultaneamente a esta motivação anterior, acentua-se a migração por trabalho e ocupações diversas. Esses migrantes procedem, sobretudo, da migração intergeracional nordestina. Na década de 1980, Almeida classificou duas frentes de migração para a "fronteira agrícola" amazônica.

[...] a primeira, que chamamos de "sulista", compõe-se de um fluxo de migrantes oriundos principalmente das regiões Sul e Sudeste, bem como de nordestinos 'reciclados'. Tem penetrado na Amazônia através do Centro-Oeste e, hoje, dirige-se prioritariamente para Rondônia e Mato Grosso. A outra, que chamamos prosaicamente de 'outros migrantes', compõe-se de um fluxo predominantemente nordestino; no entanto, inclui também capixabas e migrantes de outras partes do país. Tem penetrado na Amazônia geralmente através do Pará, e já se defronta com o fluxo sulista na região mato-grossense e do sudeste do Pará (ALMEIDA, 1984, p. 39).

No sudeste do Pará, dos imbricamentos dos discursos dos "pioneiros" e dos "bandeirantes", a definição dos Outros das relações socioculturais se torna objeto das lutas de representação. Numa avaliação, a migração ganha sentidos positivos quando se trata de definir a região em alteridade com o norte do Estado ou à Amazônia. A migração converte-se no critério cultural de identidade regional, instrumento mobilizador do sentimento de pertencimento de uma população socioculturalmente heterogênea. Noutra, a migração internamente é construída como problema, quando integrada por pobres, sobretudo maranhenses e nordestinos.

Desde então, os maranhenses passaram a ser indesejados ou apenas demandados como mão de obra, quando a (re)fundação do território - "eliminado" o índio - tornava "imperiosa" nova classificação sociocultural que designasse aquele a ser "etnicizado" e fornecesse os "braços" para o trabalho mais penoso e degradante de exploração econômica - as atividades que "possuíam" o território.

O sul do Pará, hoje, tem pouco mais de $10 \%$ de pessoas nascidas no Estado. O restante é originário de uma corrente migratória que formou uma cultura de perfeita homogeneidade, resultado de muita luta, trabalho incansável e crença na região para onde vieram como verdadeiros bandeirantes (JORNAL CONVERGÊNCIA, 1993, p. 6).

Novos Cadernos NAEA • v. 17 n. 1 • p. 203-223 • jun. 2014 
Este é um discurso de características político-panfletárias, que tenta afirmar uma identidade regional coesa. Seu contexto é o da demanda pela separação político-administrativa do Pará. E, como outros discursos de regionalização, realizam classificações práticas e orientadas para a produção de efeitos sociais (BOURDIEU, 1989).

Nos discursos que visam estabelecer as fronteiras "exteriores" e delimitar uma identidade para a região desde a década de 1970, sobressaem-se, de uma parte, enunciações que remetem a um ideal de identidade representado pelo Centro-Sul do país e, de outra, (re)criam um Outro representado pela Amazônia nortista (da qual espera-se manter separado). Além disso, no âmbito da fronteira "interior" têm-se discursos que identificam os Outros que a suposta identidade regional não quer ser/assumir. A questão é como excluir os “indesejáveis", isto é, como invisibilizá-los e eliminá-los da identidade regional.

Quem são "os verdadeiros bandeirantes"? Já aqui, o discurso que até então parecia coeso, expõe suas fraturas. A narrativa dos "bandeirantes" ou dos "pioneiros" nunca incluiu a maioria dos sujeitos da história vivida. Mas, ela tem atuado com a força de delimitar "origens" e destacar personagens e seus papéis, especialmente na história das ocupações de novos espaços físico-geográficos no interior do território nacional.

O discurso sobre o migrante bandeirante no sudeste do Pará dialoga com o mito do bandeirante construído pelos paulistas: "aparece como um personagem heróico, capaz de feitos importantes, graças ao seu espírito de mando e ousadia nos empreendimentos" (SANTOS, 2008, p. 31). É o discurso de uma elite políticoeconômica predominantemente originária do centro-sul, que visa naturalizar uma divisão da realidade marcada pelas desigualdades na ocupação do território, pela exploração predatória dos recursos naturais e pelo "rebaixamento" da maioria da população migrante, como mão de obra disponível e barata, podendo, inclusive, ser submetida a regime de trabalho escravo.

Em 2001, um fazendeiro de Rondon do Pará, acusado de utilizar trabalho escravo e de assassinar trabalhadores migrantes, inclusive, naquele momento, suspeito de mando do assassinato do trabalhador maranhense e pai de família Manoel Ferreira dos Santos, respondeu ao Jornal do Brasil (2001, p. 7): "O que falta na região é mão de obra qualificada. Esses vagabundos não querem trabalhar". Em 2005, Carlos Xavier, então presidente da Federação da Agricultura do Estado do Pará (Faepa), discursando para lideranças ruralistas, em Belém, criticou a representação do Pará como "Estado bandido, grileiro e escravagista", e afirmou: "Vocês são heróis, homens dignos e sérios que produzem alimento e conseguem manter a economia do País estabilizada. Este é o produtor rural paraense" 
(DIÁRIO DO PARÁ, 16/03/2005. Cad. Cidades, p. 8). No sul e sudeste do Pará, os "bandeirantes" querem "ordem" e não desejam ser constrangidos nas suas atividades econômicas.

O presidente do Sindicato Rural de Redenção, Luciano Guedes, argumenta com o passado dos bandeirantes para justificar a derrubada de árvores seculares para tornar rentáveis milhares de hectares transformados em pastos e plantações de soja. [...] 'Por que sou considerado um depredador, se estou ajudando a construir o Pará, como fizeram os desbravadores de outras regiões?”'(O LIBERAL. Belém, 11/11/2005. Sul do Pará, p. 3).

O imbricamento de interesses e visões de antigas elites regionais e dos "novos" bandeirantes produz e veicula um discurso das vantagens da migração, desde que cada grupo social assuma o "seu lugar" no processo de ocupação do território.

O amazônida, prisioneiro da Natureza, assiste empolgado a penetração das matas pelas possantes e complexas máquinas que constroem a Transamazônica. [...] O amazônida, despertado pelas Trombetas da Civilização, vai desmentir sociólogos e historiadores, unindo suas forças e sua coragem à técnica e experiência do sulista à bravura e perseverança do nordestino [...]. Já era tempo de o Sul vir de encontro ao Norte (BARROS, 1971).

Nesta representação da migração, as contribuições do caboclo e do nordestino são aquelas necessárias ao enfrentamento do trabalho braçal, em condições extremamente adversas. Além disso, o "nativo"/ caboclo é um sujeito em "extinção", estágio a ser superado. Já a contribuição do "sulista" diz respeito à técnica e à experiência, isto é, deverá ocupar posição de planejamento, de controle do processo e das formas de exploração econômica do território.

Nesse discurso predomina a intenção de promover a (des)territorialização dos nativos, nas dimensões físico-econômica, política e cultural. No caso dos migrantes pobres, a dinâmica imaginada é aquela na qual deve predominar uma territorialização apenas precária desses sujeitos no novo espaço. Já o modelo civilizacional, supostamente representado pelos migrantes do centro-sul, constitui-se na representação daquele que funda (ou deve fundar) o novo território.

Que autoridade tem esse discurso? Esse é um discurso que participa diretamente da luta para definir a realidade. Por isso, é constituído e constituinte das relações de força presentes na sociedade (BOURDIEU, 1989), inclusive porque, muitas vezes, são enunciados a partir de espaços institucionalizados como legítimos lugares de fala, como a imprensa, ou pela exibição de um poder de representação social ou política que confere autoridade ao discurso.

No sudeste do Pará, disputa-se o espaço, especialmente como exercício de Novos Cadernos NAEA • v. 17 n. 1 • p. 203-223 • jun. 2014 
poder e como fonte de recursos. Os sujeitos são aqueles que se autodenominam colonizadores, como neste trecho de declaração de princípios de entidades patronais do Pará: “O Pará, notadamente na sua área sul-sudeste, foi ocupado por brasileiros que ansiavam participar de um amplo processo colonizador" (CORREIO DO TOCANTINS, 2008, p. 2). Esses colonizadores fazem questão de destacar sua distinção (separação) da Amazônia e não desejam ter seus interesses contrariados pelo Estado. Exemplo disso é a fala de José Diamantino, paulista de Regente Feijó, dono de concessionária de veículos e fazendas no sudeste do Pará.

É verdade que se diga, porém, que esse pessoal que chegou aqui a vinte, trinta anos, na verdade foram chamados para aqui investir. Foram chamados na época da construção da rodovia Transamazônica (BR-230) a desenvolver a região. Veio gente grande, média e pequena, isso do ponto de vista do potencial econômico para desbravar isso aqui. É claro que numa região pioneira, tudo tem um caráter precário. Criou-se aqui na Amazônia alguns costumes, que são diferentes da Europa e dos Estados Unidos. Essa relação trabalhador-empregador na zona rural diferente daqui do Pará, em comparação com o Estado de São Paulo. Como aqui o Governo não dava médico, serviço dentário, educação e outras obrigações previstas em Lei, que seria o normal. Ao longo do tempo como o Estado não aparecia, o proprietário bancava tudo isso. No sul do Pará não se tinha a cultura de registrar os empregados, assim como, a bem pouco tempo, não era costume na zona urbana se registrar as empregadas domésticas. Após uma maior presença do Estado, acho que essas questões acabam por se resolver com o tempo, não com a força (DIAMANDINO, 2004, p. 3).

Esse texto é interessante para observar como os discursos de identidade envolvem usos estratégicos. Quando infere que na Amazônia criaram-se costumes diferentes dos da Europa, dos Estados Unidos e de São Paulo (o modelo colonizador), qualifica-se a fronteira como espaço precário e culpa-se o Estado pelos [maus] costumes. O modelo civilizacional é o mesmo e os seus sujeitos também, mas justificam-se os supostos contrastes como ocorrências naturais das circunstâncias envolvidas (precárias). Subjacente a esse discurso, há também a afirmação da visão do espaço físico-natural amazônico - por isso, nesse texto, a região é integrada à Amazônia - como o condicionante dos desvios do modelo idealizado, algo que se construiu como cultura, contrariamente aos seus sujeitos. Enfim, uma imposição do mundo natural que naturaliza também as relações sociais construídas.

Se o Estado não deve agir com sua força contra esse sujeito colonizador, por outro lado, sujeitos em condições de subalternidade, que têm se organizado e disputado espaços físicos e simbólicos e as perspectivas de desenvolvimento 
do território, são nomeados nos discursos desses colonizadores como casos de polícia, contra os quais o Estado deve aplicar toda a sua força repressiva. Em 2006, quando os índios Xikrin ocuparam as instalações da Companhia Vale do Rio Doce (CVRD), na Serra dos Carajás, reivindicando o cumprimento dos repasses financeiros, objeto de acordo compensatório aos povos locais, a CVRD veio a público afirmar que os índios eram caso de polícia. O jornal Opinião (2 a 3/11/2006), além de divulgar a "nota de esclarecimentos" da CVRD, publicou uma página inteira de reportagem sobre o assunto, na qual reproduz um discurso de rebaixamento da ação dos indígenas, classificada como atos de violência e de desordem, uma clara adesão à versão da Companhia. $\mathrm{Na}$ fala do diretor executivo de Assuntos Corporativos da mineradora, Tito Martins, predominaram representações que visavam desqualificar e criminalizar a ação dos indígenas.

[...] As empresas privadas não podem mais conviver com ilegalidades promovidas por índios, que vêm lançando mão de ações que podem ser caracterizadas como crimes de cárcere privado, roubo, extorsão, dano, invasão de estabelecimento industrial, formação de quadrilha, perigo de desastre ferroviário e desobediência (OPINIÃO, Marabá, 2-3/11/2006, p. 4).

A naturalização de um modelo de desenvolvimento e a inevitabilidade de seus males têm sido discurso difundido como forma de convencimento que, nesse processo, parcela da sociedade deve mesmo "pagar os custos" negativos resultantes.

O Correio do Tocantins (9-12/02/2007. Cad. 3, p. 3), ao fazer referência à interdição da Estrada de Ferro Carajás pelos Guajajara, em 2006, além de ressaltar que as etnias indígenas "não puderam opinar sobre seu próprio destino" quando da construção da ferrovia, assinalava: "Resta à Vale rezar para que a moda não pegue, e que as populações marginalizadas de Carajás não sigam o exemplo dos indígenas".

Em 2007, depois da ocupação da Estrada de Ferro Carajás pelo Movimento dos Sem Terra (MST), em Parauapebas, o presidente da CVRD, Roger Agnelli, afirmou: "O MST é um caso de polícia. É uma questão de ordem e de estado de direito" (CORREIO DO TOCANTINS, 30/11-3/12/2007. Cad. 3, p. 3). Na ocasião, em outubro de 2007, O Liberal (8/10/2007. Poder, p. 9) divulgou a notícia da possibilidade de fechamento da ferrovia, com os seguintes destaques: "MST deixa Exército de prontidão" e "Fazendeiros da região estão em alerta, temendo novas invasões de propriedades".

Não é estranho que a "Declaração de princípios" divulgada por entidades patronais do Estado do Pará (Belém, 14/04/2008), tenha ocorrido justamente 
quando a CVRD estava sendo confrontada diretamente por movimentos campesinos e garimpeiros. Esse documento expressava a coesão da classe patronal/empresarial atuando em diversos empreendimentos econômicos na região, desde o agronegócio às empresas de mineração.

Ainda que não seja objeto desse trabalho, vale ressaltar que, neste contexto, coexistem as contra-narrativas da colonização, e elas participam da disputa pela região entendida como "aproveitamentos estratégicos diferenciados do espaço. $\mathrm{Na}$ luta pela posse do espaço ele se fraciona, se divide em quinhões diferentes para os diversos vencedores e vencidos; assim, a região é um botim de uma guerra" (ALBUQUERQUE JR., 2001, p. 26). Além disso, os grupos subalternizados têm sido portadores de um projeto de refundação territorial mais universalizante do que aquele cujos portadores ("colonizadores") estão defendendo: acima de tudo, seu patrimônio e seus lucros. Por isso, para esses últimos, é uma "questão de ordem e de estado de direito", isto é, da existência de um arbítrio hierarquizador, disciplinador e punitivo.

\section{CONSIDERAÇÕES FINAIS}

Em ambas as regiões - sul do Maranhão e sudeste do Pará - tem-se colocado em prática os usos da memória para construir mitos fundadores que possam justificar pretensões de separatismo político-territorial, isto é, alcançar certos níveis de consenso social. Contudo, a análise de seus contextos de enunciação e monumentalização evidenciam que essa memória é discricionária e visa certa hierarquia e ordenamento social.

Está em jogo (como interesse articulador) não apenas o que comumente é identificado como repartição de poder político entre grupos de elites e a ampliação do acesso aos recursos públicos, mas, principalmente, a pretensão de estruturação de arranjos regionais de poder sobre o território e as relações sociais, para viabilizar um determinado modelo de desenvolvimento.

O Estado desejado e orquestrado por esses agentes (ainda no atual estado do Pará) é aquele que vai exercer seu arbítrio hierarquizador, disciplinador e punitivo, visando garantir o modelo expropriador (do trabalho e dos bens naturais) à custa da subordinação da maioria da população, tais como camponeses, indígenas, extrativistas, quilombolas, ribeirinhos e trabalhadores pobres das cidades, considerados empecilhos ao desenvolvimento, quando não aceitam passivamente submeter-se ao projeto de acumulação concentrada de capitais. 
Neste sentido, não está em questão uma mudança política com consequências na direção de outro modelo econômico-social ou da gestão dos recursos públicos, mas os mecanismos de eficiência pela distribuição da máquina administrativa e de poder coercitivo no cumprimento das direções hegemônicas no Estado.

Nisso, a reflexão sobre o processo de invenção dos mitos fundadores, pela eliminação de outros agentes da história e sujeitos de memória, dão aos indivíduos e coletividades dessas regiões a possibilidade de refletir sobre o seu lugar na história. E colocar uma questão: quais são as fronteiras da expatriação, experiência comum da maioria de nós? Aonde nossos destinos se dividem?

\section{REFERÊNCIAS}

ALBUQUERQUE JR., D. M. de. A invenção do Nordeste e outras artes. 2. ed. São Paulo: Cortez; Recife: FJN; Massangana, 2001.

ALBUQUERQUE JR., D. M. de. As invenções e Representações em Torno do Semi-Árido - implicações na educação. Manuscrito oriundo de exposição oral, [s.d.], 23p..

ALMEIDA, A. L. O. de. A expansão da fronteira. Ciência Hoje, v. 2, n. 10, p. 38-39, jan./fev., 1984.

AMORIM, J. R. R. (Org.). Notícias históricas de Grajaú. Imperatriz: Ética, 2008.

ANDRADE, M. C. de. Paisagens e problemas do Brasil. 5. ed. rev. atual. São Paulo: Brasiliense, 1977.

BAKHTIN, M. Marxismo e filosofia da linguagem. 2. ed. São Paulo: Hucitec, 1981.

BAKHTIN, M. Questões de literatura e de estética. A teoria do romance. 3. ed. São Paulo: Unesp, 1993.

BARROS, João Maria. Futuro e Grandeza. Revista Itatocan, Marabá, jan. 1971, ano 8, n. 1 .

CÂNDIDO SÁ. Transamazônica humanizando. Itatocan Jornal. Marabá, dez. 1971. Edição do Natal, p. 2. 
BECKER, B.; MACHADO, L. Uma nova fronteira para o século XXI. Ciência Hoje, v. 1, n. 3, p. 45-50, nov./dez., 1982.

BHABHA, H. O local da cultura. Belo Horizonte: Editora UFMG, 2003. BOURDIEU, P. O poder simbólico. Rio de Janeiro: Bertrand Brasil, 1989.

CERTEAU, M. de. A invenção do cotidiano. 1. Artes de fazer. 6. ed. Petrópolis: Vozes, 1994.

CHARTIER, R. O Mundo como Representação. Estudos Avançados, São Paulo, v.11, n. 5, p. 173-191, 1991.

COELHO, C. B. (Coord.). Memórias de Pastos Bons. Imperatriz: Ética, 2005. CORREIO do Tocantins. A luta dos desbravadores contra os índios, as feras e os insetos, Cad. 2, p. 2, 5-8 abr. 2004.

CRESCIMENTO trouxe invasores e impactou a vida dos indígenas. Correio do Tocantins, Marabá, 9 a 12 fev. 2007, Cad. 3, p. 3.

DECLARAÇÃO de princípios das lideranças empresariais, profissionais e de trabalhadores do Estado do Pará, Belém do Pará, 14 de abril de 2008. Correio do Tocantins. Marabá, 19 a 21 mai. 2008, Cad. 2, p. 2.

DIAMANTINO FERREIRA, W. A. Maranhão do Sul: o estado da integração nacional. Imperatriz: Ética, 2007.

FRANKLIN, Adalberto; CARVALHO, João Rênor F. de (Orgs.). Francisco de Paula Ribeiro: desbravador dos sertões de Pastos Bons: a base geográfica e humana do sul do Maranhão. Imperatriz, MA: Ética, 2007.

GUILLEN, I. C. M. O sertão e a identidade nacional em Capistrano de Abreu. In: BURITY, J. A. (Org.). Cultura e identidade: perspectivas interdisciplinares. Rio de Janeiro: DR\&A, 2002, p. 105-124.

GUIMARÃES NETO, R. B. Personagens e memórias: territórios de ocupação recente na Amazônia. In: CHAULHOUB, S. et al. (Orgs.). Histórias de cousas miúda: capítulos de história social da crônica no Brasil. Campinas: Editora Unicamp, 2005. p. 519-546.

ILUSÃO acaba em morte. Jornal do Brasil. Rio de Janeiro, Caderno Brasil, p. 7, 11 dez. 2001.

JORNAL Convergência, Marabá, n. 18, p. 6. 11-18 nov. 1993. 
LOUREIRO, V. R. Amazônia: uma história de perdas e danos, um futuro a (re) construir. Estudos Avançados, São Paulo, v. 16, n. 45, p. 107-121, 2002.

MARTINS, H. T. A Fragmentação do Território Brasileiro: a criação de novos estados no Brasil. Caderno CRH, Salvador, n. 35, p. 263-288, jul./dez. 2001.

MARTINS, J. de S. [entrevista]. Frentes de expansão: os novos espaços dos velhos problemas. Travessia, São Paulo, p. 5-8, jan./abr., 2004.

MARTINS, José de Souza. Migrações e tensões na Amazônia. O São Paulo. São Paulo, 25 abr. a 01 mai. 1980, p. 6-7.

MENDES, Eduardo. Agronegócio. Ruralistas reagem a reservas extrativistas. Diário do Pará. Belém, Cad. Cidades, p. 8, 16 mar. 2005.

MORBACH, A. Os tempos pioneiros da Castanha do Pará em Marabá. In: BRAZ, A. et. al. Marabá. A história de uma parte da Amazônia, da gente que nela vivia e da gente que a desbravou e dominou, fazendo-a emergir para a civilização. De 1892 até nossos dias. Marabá: Prefeitura Municipal, 1984. p. 118-123.

MORBACH, M. Amazônia in concert. 1997. 72f. Dissertação (Mestrado em Comunicação Semiótica) - Pontifícia Universidade Católica de São Paulo, São Paulo, 1997.

MST deixa Exército de prontidão; Fazendeiros da região estão emalerta, temendo novas invasões de propriedades. O Liberal, Belém, Poder, p. 9, 8 out. 2007.

NESSE NEGÓCIO não existe santinho. Entrevista com José Francisco Diamantino. Diário do Pará. Belém, 17 jul. 2004, Regional, p. 3.

PECUARISTA defende zoneamento da Amazônia. O Liberal. Belém, Sul do Pará, p. 5, 11 nov. 2005.

PETIT, P. Chão de promessas: elites políticas e transformações econômicas no Estado do Pará pós-1964. Belém: Paka-Tatu, 2003.

REIS, A. A. M.; PEREIRA, M. R. B. Carolina: apogeu, declínio e ressurgência. Imperatriz: Ética, 2007.

SÁ, C. Entrevista. Jornal Itatocan, Edição do Natal, Marabá, p. 2, dez. 1971.

SANTOS, F. L. de S. et al. Identidades Sul-Maranhenses: subsídios à prática didático-pedagógica no Ensino Médio. Imperatriz: Ética, 2009. 
SANTOS, F. L. de S. Herói em construção. Revista de História da Biblioteca Nacional, Rio de Janeiro, ano 3, nº 34, p. 30-34, julho 2008. (Dossiê Bandeirantes). SILVA, I. S. A migração como mito fundador e outras metáforas: narrativas da colonização no sudeste do Pará. Escritas, Goiânia, v. II, n. 2, p. 59-74, 2010.

TEAO, K. M. Mito e história: estratégias políticas do neozapatismo. In: ENCONTRO INTERNACIONAL DA ANPHLAC, 8. 2008, Vitória. Anais... Vitória, 2008. 11p. Disponível em: www.anphlac.org/periodicos/anais/ encontro8/kalna\%20_teao.pdf. Acesso em: 20 maio. 2010.

VALE cancela repasse financeiro aos índios Xikrin. Opinião. Marabá, 2 a 3 nov. 2006, p. 4.

VAMOS ter quatro siderúrgicas no País. Correio do Tocantins, Marabá, 30 nov. a 3 dez. 2007, Cad. 3, p.3. 
